\title{
STRUCTURAL MONITORING AND LIFE-TIME ASSESSMENT OF MEDIEVAL TOWERS
}

\author{
A. CARPINTERI AND G. LACIDOGNA \\ Department of Structural and Geotechnical Engineering, Politecnico di Torino, 10129 Torino, Italy
}

\section{ABSTRACT}

The problem of structural stability of two medieval masonry towers is addressed. The geometrical and structural aspects of the towers were analysed and non-destructive tests were performed to assess the evolution of damage phenomena. The damage processes underway in some portions of the masonry were monitored using the Acoustic Emission (AE) technique. This method makes it possible to estimate the amount of energy released during the fracture process and to obtain information on the criticality of ongoing processes. Finally, an ad hoc theory based on fractal concepts for assessing the stability of masonry structures from the data obtained with the AE technique is proposed.

\section{INTRODUCTION}

Non-destructive and instrumental investigation methods are currently employed to measure and check the evolution of adverse structural phenomena, such as damage and cracking, and to predict their subsequent developments [1,2]. This study addresses some of the afore-mentioned problems deemed of special significance.

Towers geometry was defined through the customary survey methods. Damage, cracking and the evolution of these phenomena over time were assessed through a number of non-destructive techniques: thermographic exams were performed on the main sets of the towers subjected to cracking phenomena; tests with jack-flats were conducted in order to evaluate the range of stresses affecting the structures; at the same time, the cracking processes taking place in some portions of the masonry structures were monitored using the Acoustic Emission (AE) technique.

The AE technique has proved particularly effective [3,4], in that it makes it possible to estimate the amount of energy released during the fracture process and to obtain information on the criticality of the process underway. According to fractal concepts, an ad hoc theory is employed to monitor masonry structures by means of the AE technique [4]. The fractal theory takes into account the multiscale character of energy dissipation and the strong size effects associated with it. With this energetic approach it becomes possible to introduce a useful damage parameter for structural assessment based on a correlation between AE activity in a structure and the corresponding activity recorded on masonry elements of different sizes, tested to failure by means of double flat-jacks.

\section{DESCRIPTION OF THE TWO TOWERS}

These masonry buildings from the $13^{\text {th }}$ century are the tallest and mightiest medieval towers preserved in Alba, a characteristic town in Piedmont (Italy). Torre Sineo (Fig. 1) is square, $39 \mathrm{~m}$ high, and leans to a side by about $1 \%$. Wall thickness ranges from 0.8 to $2 \mathrm{~m}$. The bearing walls are $a$ sacco, i.e., consist of brick faces enclosing a mixture of rubble and bricks bonded with lime and mortar. Over a height of $15 \mathrm{~m}$, the tower is incorporated in a later building. Torre Astesiano (Fig. 2) has a similar structure, but has a rectangular base. The filling material is more organised, with brick courses arranged in an almost regular fashion, which, however, are not connected with the outer wall faces. In this case too, the total thickness of the masonry ranges from $2 \mathrm{~m}$ at the bottom to $0.8 \mathrm{~m}$ at the top. Total height is ca $36 \mathrm{~m}$ and the tower does not lean on any side. It is also incorporated in a later building, approx. $15 \mathrm{~m}$ high, built when the tower had been completed. 


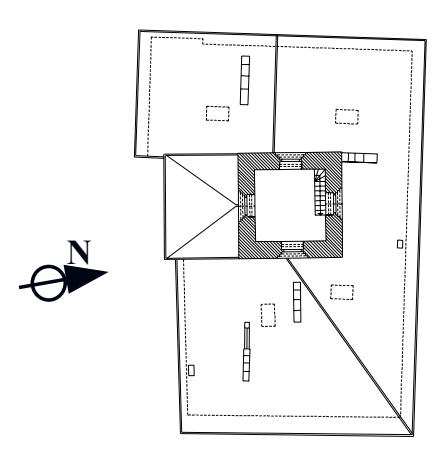

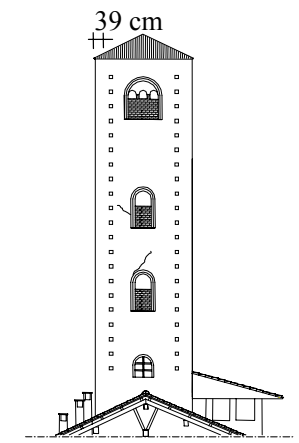

West side

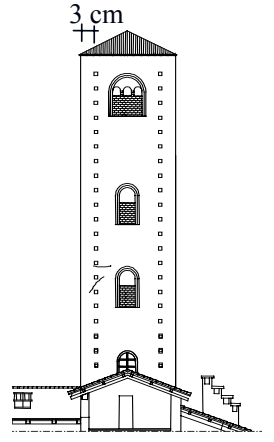

South side

Figure 1: Torre Sineo. Plan and elevations of two sides of the tower. Notice the presence of cracks near the openings and the deviation from verticality of the tower.
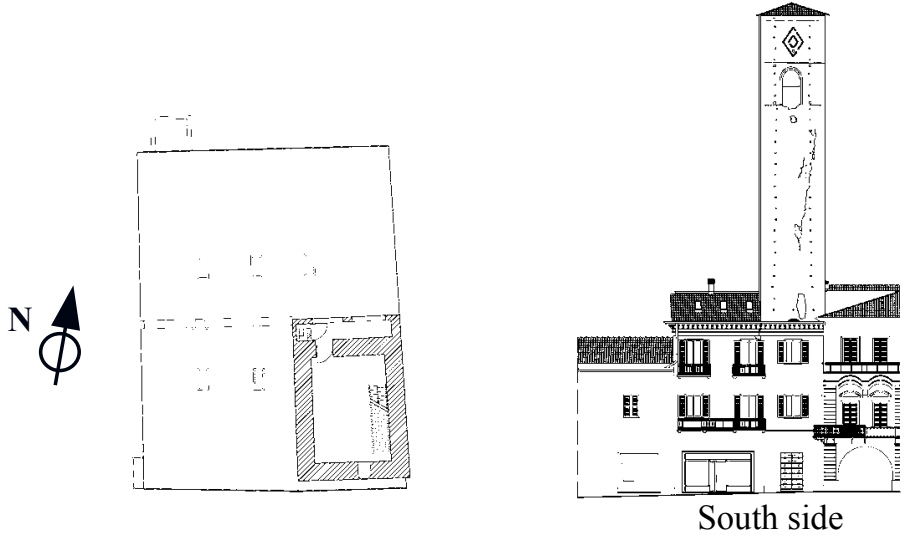

Figure 2: Torre Astesiano. Plan and elevation view of the tower. Notice the presence of the main crack in the upper part of the tower.

\section{NON-DESTRUCTIVE EVALUATION TESTS}

The geometry of the towers and the buildings they are embedded in was fully acquired and organized within a CAD system. The positions of the openings and the variations in the thickness of the tower walls was carefully recorded, together with the positions of the main cracks observed in the two structures. Tests with single and double flat-jacks were performed on the masonry walls of both towers. These tests were designed to estimate stress values in the masonry at different levels and to assess the elastic modulus and failure strength in situ.

Thermovision was used to identify areas with structural anomalies. Figure 3 shows a photograph of a badly damaged portion of the Sineo Tower (a) and compares it with the relative thermographic image (b). Some of the temperatures obtained are listed in the table: the coldest masonry points might reflect the presence of a crack. Figure 4 compares a thermographic image and a photograph of a damaged portion of the Torre Astesiano. From the thermographic image it can be seen that the average temperatures of the masonry zones in the proximity of the vertical crack are higher than the temperatures recorded at the crack. The reduction in temperature, in fact, reflects the gaps in the bricks along the crack.

The cracking processes taking place in some portions of the masonry structures were monitored using the Acoustic Emission (AE) technique. Crack opening, in fact, is accompanied by the emission of elastic waves which propagate within the bulk of the material. These waves can be captured and recorded by transducers applied to the surface of the structural elements [6]. 


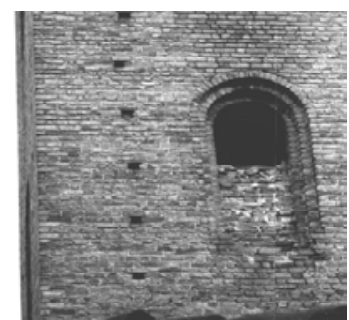

(a)

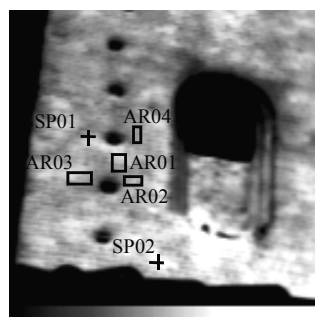

(b)

\begin{tabular}{ll}
\hline Points & Temperature ${ }^{\circ} \mathrm{C}$ \\
\hline Spot 1 & $30.2^{\circ} \mathrm{C}$ \\
Spot 2 & $32.7^{\circ} \mathrm{C}$ \\
AR 01 mean & $31.6^{\circ} \mathrm{C}$ \\
AR 02 mean & $30.8^{\circ} \mathrm{C}$ \\
AR 03 mean & $31.6{ }^{\circ} \mathrm{C}$ \\
AR 04 mean & $30.8^{\circ} \mathrm{C}$ \\
\hline
\end{tabular}

Figure 3: Torre Sineo. Thermography: view of portion analysed (a). Temperature diagram in the 28.6-32. $9^{\circ} \mathrm{C}$ range (b).

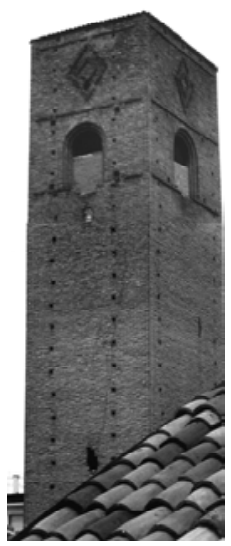

(a)

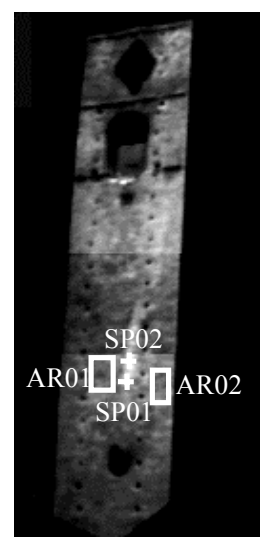

(b)

\begin{tabular}{ll}
\hline Points & Temperature ${ }^{\circ} \mathrm{C}$ \\
\hline Spot 1 & $30.2^{\circ} \mathrm{C}$ \\
Spot 2 & $32.5^{\circ} \mathrm{C}$ \\
AR 01 mean & $31.6^{\circ} \mathrm{C}$ \\
AR 02 mean & $31.8^{\circ} \mathrm{C}$ \\
\hline
\end{tabular}

Figure 4: Torre Astesiano. Thermography: view of portion analysed (a). Temperature diagram in the $28.6-32.9^{\circ} \mathrm{C}$ range (b).

\section{AE DAMAGE DETECTION OF THE TOWERS}

For the Sineo Tower, through AE monitoring, two cracks were detected in the inner masonry layer at the seventh floor level (Fig. 1). The monitoring process revealed an on-going damaging process, characterized by slow crack propagation inside the brick walls. In the most damaged zone, crack spreading had come to a halt, the cracks having achieved a new condition of stability, leading towards compressed zones of the masonry. In this particular case it can be seen that, in the zone monitored, each appreciable crack advance is often correlated to a seismic event. In the diagram shown in Figure 5, the cumulative AE function relating to the area monitored is overlaid with the seismic events recorded in the Alba region during the same time period; the relative intensity of the events is also shown [4].

A similar behaviour was observed for the Torre Astesiano. This structure was monitored by means of two transducers applied to the inner masonry layer of the tower, at the fourth floor level near the tip of the large vertical crack. The results obtained during the monitoring period are summarised in the diagram in Figure 5. In this case too, it can be seen how the damage to the masonry and the propagation of the crack, as reflected by the cumulative number of EA events, evolved progressively over time. A seismic event of 4.7 degrees on the Richter scale occurred during the monitoring period: from the diagram we can see how the cumulative function of EA events grew rapidly immediately after the earthquake. 

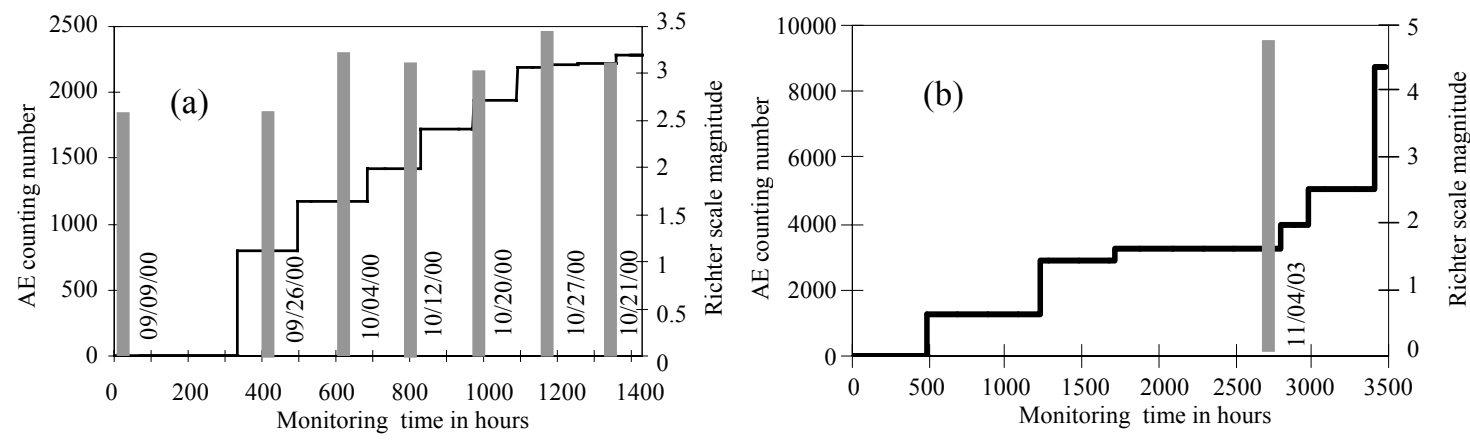

Figure 5: AE and seismic events. Torre Sineo (a), Torre Artesiano (b).

\section{A FRACTAL CRITERION FOR AE MONITORING}

Fragmentation theories have shown that during microcrack propagation energy dissipation occurs in a fractal domain comprised between a surface and the specimen volume $V$ [5]. On the other hand, during microcrack propagation, acoustic emission events can be clearly detected. Since the energy dissipated, $E$, is proportional to the number of AE events, $N$, the critical density of acoustic emission events, $\Gamma_{\mathrm{AE}}$, can be considered as a size-independent parameter:

$$
\Gamma_{\mathrm{AE}}=\frac{N_{\max }}{V^{D / 3}},
$$

where $\Gamma_{\mathrm{AE}}$ is the fractal acoustic emission density, $N_{\max }$ is evaluated at the peak-stress $\sigma_{\mathrm{u}}$ and $D$ is the so-called fractal exponent comprised between 2 and 3. Eq. (1) predicts a volume-effect on the maximum number of AE events for a specimen tested to failure [4].

The extent of structural damage observed during the monitoring period, identified by the parameter $\eta$, can also be correlated to the rate of propagation of the microcracks. If we express the ratio between the cumulative number of $\mathrm{AE}$ events recorded during the monitoring process, $N$, and the number obtained at the end of the observation period, $N_{\mathrm{d}}$, as a function of time, $t$, we get the damage time dependence on AE:

$$
\eta=\frac{E}{E_{\mathrm{d}}}=\frac{N}{N_{\mathrm{d}}}=\left(\frac{t}{t_{\mathrm{d}}}\right)^{\beta_{\mathrm{t}}} .
$$

In eq.(2), the values of $E_{\mathrm{d}}$ and $N_{\mathrm{d}}$ do not necessarily correspond to peak stress conditions $\left(E_{\mathrm{d}} \leq\right.$ $\left.E_{\max } ; N_{\mathrm{d}} \leq N_{\max }\right)$ and the $t_{\mathrm{d}}$ parameter must be construed as the time during which the structure has been monitored. By working out the $\beta_{\mathrm{t}}$ exponent from the data obtained during the observation period, we can make a prediction as to the structure's stability conditions. If $\beta_{\mathrm{t}}<1$, the damaging process slows down and the structure evolves towards stability conditions, in as much as energy dissipation tends to decrease; if $\beta_{\mathrm{t}}>1$ the process becomes unstable, and if $\beta_{\mathrm{t}} \cong 1$ the process is metastable, i.e., though it evolves linearly over time, it can reach indifferently either stability or instability conditions.

\section{FLAT-JACK AND AE TESTS}

In order to assess the extent of damage in the zone monitored using the AE technique, a compressive test was conducted on the masonry through the combined use of double jacks and AE sensors (Fig. 6). For the Astesiano Tower, compressive tests were performed on three different 
masonry sections at third level. The prismatic masonry volumes tested in compression were delimited crosswise by vertical cuts (Fig. 6). The tests are in keeping with the procedures specified in ASTM 1991 [7], other than for the vertical cuts produced in order to eliminate, in the element damaged, the influence of the adjacent masonry portions. The experimental results are summarised in the table of Figure 6 . The table shows that in compressive tests the cumulative number of AE events increased with increasing specimen volume. From a statistical analysis of the experimental data, parameters $D$ and $\Gamma_{\mathrm{AE}}$ (eq. (1)) can be quantified [4]. Parameter $D$ represents the slope, in the bilogarithmic diagram, of the curve correlating $N_{\max }$ to specimen volume. By best-fitting, we obtain $D / 3 \cong 0.743$, so that the fractal exponent, as predicted by fragmentation theories, turns out to be of between 2 and $3(D \cong 2.23)$. Moreover, the critical value of fractal AE density turns out to be: $\Gamma_{\mathrm{AE}} \cong 8.00 \mathrm{~cm}^{-2.23}$.

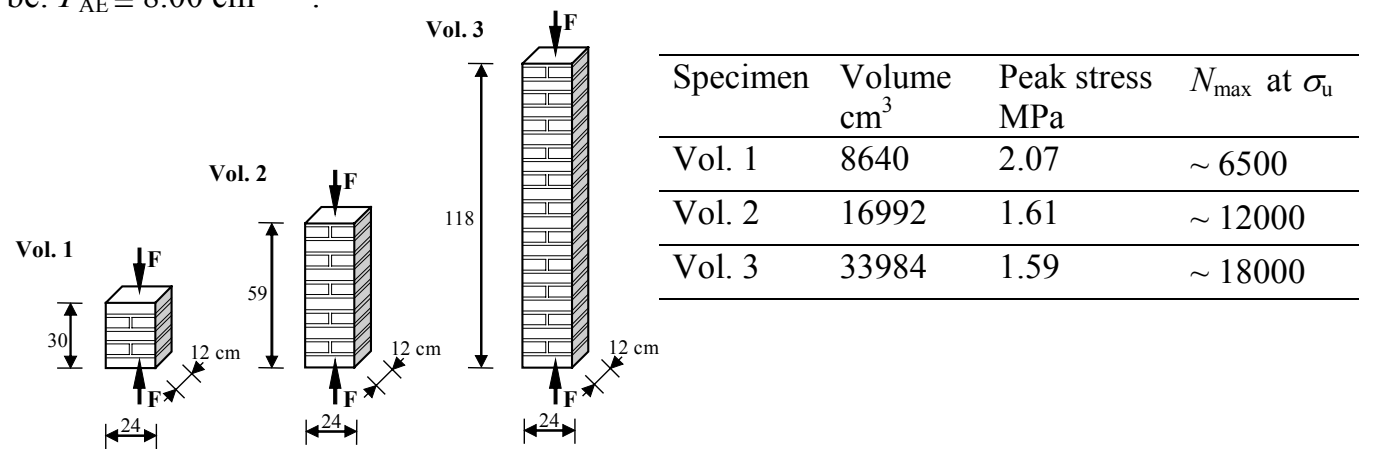

Figure 6: Masonry elements tested in compression by means of double flat-jacks and AE sensors.

7 DAMAGE LEVEL OF THE TOWERS

During the observation period, which lasted 60 days for the Sineo Tower and 146 days for the Astesiano Tower, the number of AE events recorded for the former was $N \cong 2250$, and for the latter it was $N \cong 9000$ (Fig. 5). Through earlier tests performed on rubble filled masonry, $80 \mathrm{~cm}$ thick, and hence characterised by appreciable discontinuities, it was ascertained that the transducers were able to pick up the AE signals from a distance of up to $10 \mathrm{~m}$ from their points of application and to a depth of $12 \mathrm{~cm}$, i.e., over a length corresponding to the thickness of the outer layer of bricks.

Since the average width of the sides of the towers is ca $500 \mathrm{~cm}$, the total volume monitored by the transducers will be: $V \cong 500 \times 2000 \times 12=1.2 \times 10^{7} \mathrm{~cm}^{3}$. From eq. (1), using fractal exponent $D \cong 2.23$ and the critical value of fractal acoustic emission density, $\Gamma_{\mathrm{AE}} \cong 8.00 \mathrm{~cm}^{-2.23}$, we obtain a critical AE number of $N_{\max } \cong 1.46 \times 10^{6}$. Introducing the values of $N_{\max }$ into eq.(2), we get $\eta \cong$ $0.154 \%$ for Torre Sineo and $\eta \cong 0.616 \%$ for Torre Astesiano. These values represent, in percentage terms, the amount of energy released with respect to the energy that would cause the ultimate damage of the monitored volumes.

Finally, in order to obtain indications on the rate of growth of the damage process in the towers, as given in eq. (2), the data obtained with the AE technique were subjected to best-fitting in the bilogarithmic plane. For the Sineo Tower, this yielded a slant $\beta_{\mathrm{t}} \cong 0.648$, for the Artesiano Tower $\beta_{\mathrm{t}} \cong 1.041$ (Fig. 7). These results confirm how the damage process stabilised in the Sineo Tower during the monitoring period, whereas for the Astesiano Tower it evolved towards a condition of instability according to a quasi-linear progression over time. In fact, if we introduce the values of $N$ and $N_{\max }$ obtained for Torre Artesiano into eq. (2), with $\beta_{\mathrm{t}}=1.041$, we get $t / t_{\max } \cong$ $7.532 \times 10^{-3}$. The lifetime of this structure is therefore defined, in terms of time before the maximum number of $\mathrm{AE}$ events is reached in the analysed zone, at about 53 years. 

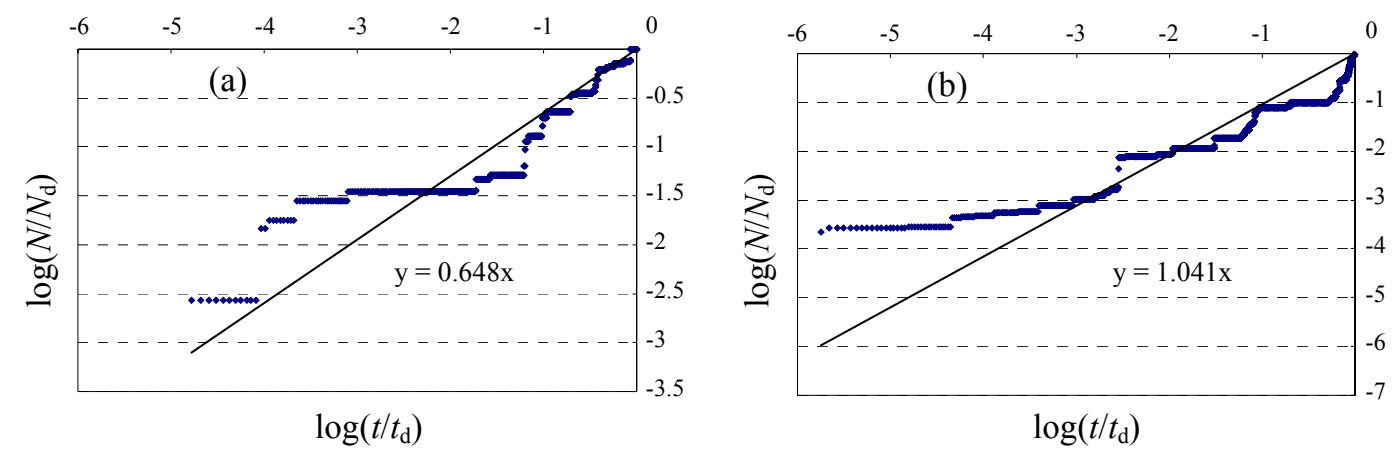

Figure 7: Evolution of damage: Torre Sineo (a), Torre Astesiano (b).

\section{CONCLUSIONS}

In view of the appreciable number of old structures still in use today, more attention should be paid to preservation and rehabilitation issues. A sound safety assessment should take into account the evolution and the interaction of different damage phenomena. In this connection, the AE monitoring can be highly effective. This technique makes it possible to introduce a useful energybased damage parameter for structural assessment which establishes a correlation between $\mathrm{AE}$ activity in a structure and the corresponding activity recorded on specimens taken from the structure and tested to failure. Moreover, by applying compressive tests through the combined use of double flat jacks and $\mathrm{AE}$ sensors, the safety of structures undergoing damage and degradation processes can be efficiently evaluated in situ.

\section{ACKNOWLEDGEMENTS}

The present research was carried out with the financial support of the Ministry of University and Scientific Research (MIUR) and of the European Union (EU). The authors would like to thank Architects M. Aprile and L. Bacco for the technical support provided in the structural monitoring.

\section{REFERENCES}

[1] Carpinteri, A., Bocca, P.: Damage and Diagnosis of Materials and Structures, Pitagora Editrice: Bologna (1991).

[2] Anzani, A., Binda, L., Mirabella Roberti, G.: The effect of heavy persistent actions into the behaviour of ancient masonry, Materials and Structures, Vol. 33, pp. 251-261 (2000).

[3] Carpinteri, A., Lacidogna, G.: Damage diagnosis in concrete and masonry structures by acoustic emission technique. Journal Facta Universitatis, Vol. 3, pp. 755- 764 (2003).

[4] Carpinteri, A., Lacidogna, G., Pugno, N.: Damage diagnosis and life-time assessment of concrete and masonry structures by an acoustic emission technique. Eds. V. C. Li, C. K. Y. Leung, K. J. Willam, S. L. Billington, pp.31-40; Proc. of $5^{\text {th }}$ Intern. Conf. on Fracture Mechanics of Concrete and Concrete Structures (FraMCos-5). Vail, Colorado-USA (2004).

[5] Carpinteri, A., Pugno, N.: Fractal fragmentation theory for shape effects of quasi-brittle materials in compression. Magazine of Concrete Research, Vol. 54, pp. 473-480 (2002).

[6] Holroyd, T.: The Acoustic Emission \& Ultrasonic Monitoring Handbook, Coxmoor Publishing Company's, Oxford (2000).

[7] ASTM: Standard test method for in situ compressive stress within solid unit masonry estimated using flat-jack measurements. ASTM C1196-91. Philadelphia (1991). 